\title{
Ética y formación personalizada: Una experiencia con profesorado universitario cubano que capacita personal directivo
}

\author{
Ethics and Personalized Training: An Experience with Cuban University Professors Training \\ Administrative Personnel
}

\section{Ética e formação personalizada: uma experiência com o corpo docente universitário cubano que capacita pessoal administrativo}

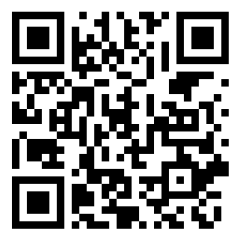

1 Profesora titular de la Universidad de Sancti Spíritus "José Martí Pérez" (UNISS), Cuba y Doctora en Psicología de la Universidad de Girona, España. Máster en Dirección. Máster en Psicopedagogía. Coordinadora del programa de posgrado "Certificado" de Maestría en Dirección. Especialista en psicología educativa y organizacional y autora de varias publicaciones relacionadas con estas temáticas. Durante más de 10 años ha coordinado proyectos de investigación de psicología organizacional y educativa.

2 Profesora titular de la Universidad de Sancti Spíritus "José Martí Pérez" (UNISS), Cuba y Doctora en Ciencias Pedagógicas de la Universidad de Oriente, Cuba. Máster en Ciencias de la Educación. Decana de la Facultad de Ingeniería de la UNISS en el período 2010-2014. Miembro del claustro del programa de posgrado "Certificado" de Maestría en Dirección. Acumula experiencia en el campo de la gestión universitaria y el desarrollo científico. Investiga en áreas relacionadas con la psicología educativa y organizacional.

${ }^{3}$ Profesora auxiliar de la Universidad de Sancti Spíritus "José Martí Pérez" (UNISS), Cuba y Máster en Estudios Sociales de la Escuela Superior del Partido "Nico López", Cuba. Directora del Centro Universitario Municipal de Cabaiguán adscripto a la UNISS. Con más de 25 años de experiencia en la Educación Superior, vinculada a la docencia de posgrado de administración para directivos del Estado y el Gobierno en la provincia de Sancti Spíritus, e investigadora en tema relativos a la gestión universitaria y los aspectos sociopsicológicos de la dirección.

${ }^{4}$ Profesor titular de la Universidad de Sancti Spíritus "José Martí Pérez" (UNISS), Cuba y Doctor en Ciencias Técnicas de la Universidad Central "Martha Abreu" de las Villas, Cuba. Director de la Dirección de Investigaciones Aplicadas de la UNISS. Miembro del claustro del programa de posgrado "Certificado" de Maestría en Dirección. Acumula experiencia en el campo de la investigación científica y la gestión universitaria. 
doi: http://dx.doi.org/10.15359/ree.22-3.3

URL: http://www.una.ac.cr/educare

CORREO: educare@una.cr

Resumen: Los postulados de Víctor García Hoz, sobre el modo de actuar del personal docente caracterizado por preferencias y actitudes, han sido poco analizados desde la enseñanza de postgrado. El presente artículo, derivado de una investigación, expone una experiencia para el fortalecimiento de la formación ética del profesorado universitario cubano que capacita personal directivo, como contribución a una educación personalizada, desde los postulados del citado autor. La metodología desarrollada desde una perspectiva interpretativa involucra al profesorado de las más altas categorías científicas y académicas de las facultades de Economía, Ingeniería y Humanidades, de la Universidad de Sancti Spíritus. La experiencia se diseña en tres fases: descriptiva, basada en la selección y lectura de documentos y grupos de discusión, para conocer los elementos esenciales de la ética profesional en el contexto universitario; empírica, donde se implementa una intervención para fortalecer la formación ética del personal docente y; valorativa, apoyada en la evaluación de la factibilidad y validez de la intervención a partir de cuestionarios a personal experto, grupos de discusión y observación participante. Los resultados obtenidos corroboraron que existe una brecha epistemológica en el análisis de la enseñanza personalizada en el postgrado y lo esencial radica en la contrastación crítica y reflexiva que el personal docente que capacita personas directivas sea capaz de hacer sobre cómo se transforman sus preceptos éticos, cómo estos impactan en sus prácticas de aula y cómo repercuten en el actuar responsable e integral de sus formados, así como en la responsabilidad compartida de la universidad y el profesorado.

Palabras claves: Educación superior; ética; ética profesional; postgrado.

Abstract: The postulates of Víctor García Hoz, on teaching staff's behaviors characterized by preferences and attitudes, have been little analyzed in postgraduate teaching programs. The present article, based on a research project, shows an experience for strengthening the ethical formation of the Cuban university teaching staff that trains administrative personnel from the postulates of the referenced author, as a contribution to personalized education. The methodology developed from an interpretative perspective is applied to professors with the highest scientific and academic categories from the Faculties of Economics, Engineering and Humanities at the University of Sancti Spiritus. The experience is designed in three phases. The first one is descriptive, based on the selection and reading of documents and discussion groups, to know the essential elements of the professional ethics in the context of the university. The second one is empirical, where intervention is implemented to strengthen the ethical education of the teaching staff. The third phase is evaluative, based on the evaluation of the feasibility and validity of the intervention from questionnaires applied to experts, discussion groups, and participant observation. The results obtained confirmed the existence of an epistemological gap in the analysis of personalized teaching in the postgraduate program. The essential lies in the critical and reflexive comparison that the teaching staff, which trains administrative personnel, can make on how its ethical precepts are transformed, how it has an impact on its classroom practices, and how it has influence on responsible and integral actions of the people being trained, as well as on the shared responsibility of both the university and teachers.

Keywords: Higher education; ethics; professional ethics; postgraduate course. 


\begin{abstract}
Resumo: Os postulados de Víctor García Hoz, sobre o modo de agir do corpo docente caracterizado por preferências e atitudes, têm sido pouco analisados no ensino de pós-graduação. O presente artigo, derivado de uma investigação, expõe uma experiência para o fortalecimento da formação ética do corpo docente da universidade cubana que forma pessoal gerencial, como contribuição para uma educação personalizada, a partir dos postulados do citado autor. A metodologia desenvolvida desde uma perspectiva interpretativa envolve o corpo docente com as mais altas categorias científicas e acadêmicas das Faculdades de Economia, Engenharia e Humanidades, da Universidade de Sancti Spíritus. A experiência desenha-se em três fases: descritiva, baseada na seleção e leitura de documentos e grupos de discussão, para conhecer os elementos essenciais da ética profissional no contexto universitário; empírico, onde se implementa uma intervenção para fortalecer a educação ética do corpo docente; valorativa, apoiada na avaliação da factibilidade e validade da intervenção a partir de questionários ao pessoal especializado, grupos de discussão e observação participante. Os resultados comprovaram que existe uma lacuna epistemológica na análise do ensino personalizado no curso de pós-graduação. O essencial está no contraste crítico e reflexivo que o corpo docente que capacita pessoas da gestão seja capaz de fazer sobre como seus princípios éticos; como estes impactam nas práticas de aula e como eles repercutem nas ações responsáveis e integrais de seus alunos, bem como na responsabilidade compartilhada da universidade e do corpo docente.
\end{abstract}

Palavras-chave: Educação superior; ética, ética profissional; pós-graduação.

\title{
Introducción
}

El panorama mundial de los últimos tiempos ha estado matizado por fenómenos que están marcando el statu quo; imprescindible referirse a la crisis mundial, la globalización de la economía y la lucha desenfrenada y desmedida de la mayoría de los países por sobrevivir en este mundo globalizado y cambiante. En un contexto así, cada vez es más complicado delimitar lo bueno de lo malo, lo correcto de lo incorrecto, lo lícito de lo ilícito, lo que la sociedad ve bien y mal, y que las personas sean capaces de formarse un proyecto coherente de vida. En contraposición, se desarrollan con frecuencia estilos de vida que se alejan de lo ético, lo honesto y lo moral, con la justificación de que dichos problemas globales lo exigen.

Parece que, en esta época llena de contradicciones y diferencias sociales en lo individual, nacional e internacional, todo tipo de comportamiento es válido para lograr mantener un nivel de vida comparable al de otros sujetos, lo que da lugar a todo tipo de actitudes como el nombre de una telenovela de la TV O Globo de Brasil "Vale todo" (Lemos y Carvalho, 1988). Ello aleja cada día más al individuo común de los seres humanos íntegros que necesita la sociedad contemporánea.

Cuba, insertada en este contexto internacional e influenciada por estos elementos, ha vivido un largo proceso de crisis económica que se agudizó a partir de los primeros años de la década de los 90 del siglo XX y que ha sido denominado por muchos politólogos cubanos como el "Período especial", el que, sin lugar a dudas, se convirtió en un terreno fértil para que determinados valores, principios éticos y normas de comportamientos de la ciudadanía se transformaran. 
doi: http://dx.doi.org/10.15359/ree.22-3.3

URL: http://www.una.ac.cr/educare

CORREO: educare@una.cr

Entre las alternativas ideadas para salir de la crisis, la más reciente -la implementación de un nuevo modelo económico y social- encaminada a lograr la eficacia y productividad, sin perder la esencia de las concepciones políticas del Estado, ha dejado como reto un campo abierto de trabajo para las universidades: responsables número uno de la formación y superación de profesionales competentes y con compromiso que requiere la sociedad.

En total sintonía con Delors (1996), quien en su informe La educación encierra un tesoro, definió cuatro ámbitos para el accionar educativo en los próximos tiempos y refirió con mucho tino: -Aprender a ser, -Aprender a saber, -Aprender a hacer, -Aprender a convivir, se busca promover conocimientos, valores y actitudes favorables con el objeto de asegurar las competencias necesarias para los grupos profesionales. Competencias que no solo son habilidades específicas, sino personales y profesionales que les permitan ejercer su carrera con ética, responsabilidad y capacidad.

También, el inicio del presente siglo trajo aparejados cambios significativos en el sector universitario, desde el punto de vista estructural, organizativo y formal; se reforzóla responsabilidad social y territorial de la universidad cubana con el desarrollo del proceso de universalización de la educación superior, a través del cual se crearon espacios de formación, extensión e investigación en todos los municipios más cercanos a las demandas de la sociedad y estrechamente relacionados con los actores. Estos nuevos espacios, donde interactúan personal educativo y estudiantes de una misma comunidad, exigen de una mayor actualización y preparación docente para lograr la formación, no solo técnica, sino también ética de sus estudiantes.

El surgimiento de estos nuevos espacios ha facilitado el perfeccionamiento de la superación del personal directivo del Estado, el gobierno y el sector empresarial, tarea que en Cuba corresponde a las universidades por encargo del gobierno nacional y que exige de una elevada contribución al desarrollo ético del estudiantado, en tanto, que en su mayoría son personas líderes comunitarias o empresariales con influencia en grandes masas; lo que es un reto para el personal docente que interviene en el proceso.

Por otra parte, en Cuba los referentes teóricos más cercanos a la temática estudiada se encuentran en investigaciones vinculadas con la ética y profesionalidad en la formación de maestros y maestras (Chacón, 1999). Dadas las condiciones económicas y sociales del país, esta autora asegura que la carrera del profesional en educación ha sufrido un cierto resquebrajamiento de su prestigio social. Evidentemente, siempre se identifica al profesorado de los niveles que anteceden a la universidad como responsables, junto a la familia, de la formación ética de sus estudiantes.

Resulta oportuno preguntarse, entonces: ¿cuán preparado está el personal profesional universitario para enfrentar los retos de formar estudiantes en estos tiempos?, ¿bastaría solo con buen dominio de los conocimientos técnicos de la profesión que se enseña?, ¿se deja de tener esta responsabilidad porque ya las personas profesionales están formadas?, ¿qué 
responsabilidad tiene la educación de postgrado con la mejora de la ética del equipo profesional que es capacitado?, ¿qué tan bien formados éticamente está el profesorado universitario en Cuba, y específicamente el que forma y capacita a personas directivas, como para irradiar con su conducta en buenas actitudes de sus estudiantes?

Con la motivación de estas y algunas otras interrogantes, por la orientación especial de la atención que se le ha dado en Cuba, en los últimos tiempos, a la capacitación del personal directivo del Estado y el gobierno, por la experiencia de más de 15 años de trabajo en un centro de investigación y formación de personal directivo y por la oportunidad que abrió el Seminario Internacional de Educación Personalizada, de la Universidad Internacional de la Rioja, el objetivo del presente artículo es exponer una experiencia para fortalecer la formación ética del profesorado universitario que capacita personas directivas, como contribución a una educación personalizada, a partir de los postulados de García (1971).

\section{Referentes conceptuales}

\section{La ética y el personal docente. Una mirada teórica desde los postulados de Víctor García Hoz}

Según García (1984), el modo de actuar del personal docente, caracterizado por sus preferencias y aptitudes, conforma su estilo, manifiesto a través de condiciones que sintetizan su capacidad didáctica, de orientación personal, de gobierno y su tono vital, expresión de su propia persona. Según este autor: "la intención perfectiva del docente se hace eficaz en la esperanza que tiene respecto de la capacidad de perfección del alumno. Esta esperanza se manifiesta en un razonable optimismo, característica esencial de este estilo educador" (p. 23).

Lo anterior constituye el punto de partida a un análisis teórico sobre ética y su implicación práctica en la labor del personal docente que forma personal directivo en la educación de postgrado en Cuba, en el que se pretenden analizar diferentes perspectivas teóricas, que incluyen, desde aspectos conceptuales hasta elementos prácticos y metodológicos que deben tenerse en cuenta en la formación ética docente, tomando como eje para el análisis los postulados de este citado autor.

\section{Aproximaciones a la definición de ética}

La alusión a la ética no ha sido, a lo largo de la historia de la humanidad, privativo de los grupos científicos y estudiosos de este aspecto, sino, muy por el contrario, ha sido abordado por la mayoría de individuos en cualquier momento de sus vidas y en muchas ocasiones, solo con un "escaso y vulgar" conocimiento del tema. Al respecto, Bañón-Gómis, Guillén-Parra y Ramos-López (2011) plantean: 
doi: http://dx.doi.org/10.15359/ree.22-3.3

URL: http://www.una.ac.cr/educare

CORREO: educare@una.cr

La dimensión ética del comportamiento humano es un dato de experiencia común, es lo propio de la condición humana que, por ser racional y libre, puede elegir entre obrar bien o mal. Cuando emitimos juicios éticos sobre determinados comportamientos juzgamos la bondad o maldad de una 'acción', una 'persona' o de un 'grupo de personas'. Por eso la ética no es ajena al mundo de las organizaciones en general. (p. 32)

Tampoco se aprecia en la bibliografía científica revisada una total concordancia entre todas las investigaciones del tema, a partir de que, aunque en la mayoría de los casos el estudio se realiza desde el campo disciplinar de la filosofía, otras ciencias también han aportado a su estudio, todo lo cual hace que no exista acuerdo común en materia de su definición.

Desde el punto de vista conceptual existen diferencias entre ética y moral que no deben ser obviadas; asimismo, desde lo histórico, la bibliografía especializada reconoce que los griegos fueron los primeros en hablar de ética y los romanos de moral; sin embargo, desde la concepción etimológica y del uso en general que de ellas hacen las personas en la vida cotidiana, las expresiones "ética" $y$ "moral" significan lo mismo.

De igual forma, según Cortina (1998), "el vocablo 'ethiké-ética' procede del griego ethos, que significa 'modo de ser' o 'carácter' igual que el término latino 'mos-moris' del que procede 'moral', de suerte que moral y ética se refieren al modo de ser o carácter que las personas van forjándose a lo largo de su vida" (p. 25). Pero, como el objetivo de este trabajo no es entrar en discusiones ni históricas ni filosóficas, se ha decidido entender ambos conceptos como sinónimos y utilizar el de ética para desarrollar la investigación.

\section{¿Qué se asumirá por ética entonces en este estudio?}

Para Marina (1995), "la ética estudia los actos del individuo y entiende por acto 'una disposición voluntaria de la inteligencia que suscita, controla y dirige las operaciones mentales para conseguir un estilo determinado de ocurrencias"' (p. 163).

Para Hortal (2002), el término ética se aplica a la conducta presumiblemente libre y responsable de una persona. Es una disciplina filosófica que investiga la conducta humana orientada hacia el bien.

Según Bautista (2005), "la ética es la disciplina del conocimiento que estudia las actitudes y costumbres del ser humano y las clasifica en virtudes y vicios, en acciones debidas e indebidas, convenientes y nocivas, con el fin de formar el carácter de los hombres al mostrar aquellos hábitos dignos de imitar" (p. 19).

Fereira (2005) define la ética como la disciplina del conocimiento que estudia las actitudes, hábitos y costumbres del ser humano. Estudia y explica el porqué de la conducta humana y propone formas deseables para actuar. 
En tanto, más recientemente, "la ética es vista como una de las actitudes personales necesarias y contemplada como la más importante para llevar a cabo con eficacia, eficiencia y de manera exitosa cualquier proyecto profesional, pues es la que otorga seguridad y confianza en el ejercicio profesional" (Vargas-Cordero, 2014, p. 276).

Se asume lo planteado por Cortina (1997), respecto a que la ética forja el carácter, los seres humanos nacen con un temperamento innato, con un conjunto de sentimientos que no han elegido y aunque resulte difícil de modificar, puede encauzarse a lo largo de su vida; por lo que, se hace posible ir moldeando un nuevo carácter. Es decir, el individuo va forjándose a sí mismo al elegir unas posibilidades vitales y rechazar otras.

En resumen, desde la percepción de quienes plantean este artículo y después de analizar las regularidades y diferencias de los conceptos anteriores, la ética es la disciplina que le establece al individuo los límites de los comportamientos aceptados o no por un determinado grupo social, la ética establece los estándares para que el individuo se autorregule y desarrolle. Pero, ¿cuál es la razón que lleva a detenerse en la ética? Todos los seres humanos poseen características innatas difíciles de modificar, mas la ética se forma y cuando el individuo la estudia y conoce que le es posible incorporar nuevos hábitos, encauzar su comportamiento o modificar su carácter, esto sugiere la idea de que no solo es importante comportarse de manera ética, sino también saber de la ética. En otras palabras, en la medida en que las personas estudian la ética se van forjando a sí mismas, se adiestran y preparan para hacer el bien no solo a ellas mismas, sino a quienes le rodean.

\section{Asimilación de la ética}

Camps (1996), en su obra El malestar en la vida pública, analiza que el ser humano por naturaleza pertenece al género animal, pero tiene desarrollada la habilidad de reflexión, análisis y deliberación profunda. Estas cualidades se basan en la capacidad de percepción, la inteligencia y el pensamiento. El desarrollo de estos elementos permite discernir lo que es nocivo y lo que es benéfico. La capacidad de deliberar permite, pues, al individuo, cuestionarse y meditar antes de tomar decisiones; es decir, en la medida en que el ser humano razona lo que es conveniente o no, entra en el campo de la ética.

En palabras de esta autora:“Deliberary decidir es algo intrínseco a la acción específicamente humana. El animal no delibera, simplemente hace lo que le dicta el instinto. No sólo hay que decidir, sino decidir bien, o lo mejor posible" (Camps, 1996, p. 170).

A partir de estos elementos se infiere que la ética asimilada en profundidad genera un proceso de transformación en el interior de la persona que se reflejará en su conducta, ya que se concibe el proceso de asimilación de la ética a partir de un conjunto de pasos o etapas en 
doi: http://dx.doi.org/10.15359/ree.22-3.3

URL: http://www.una.ac.cr/educare

CORREO: educare@una.cr

espiral ascendente que van desde la reflexión y deliberación, la adquisición de conciencia, la distinción entre lo conveniente y lo nocivo, la adopción de principios sanos, la asunción de deberes de manera voluntaria y la actuación de manera íntegra y responsable.

El proceso de asimilación de la ética analizado permite, en esta investigación, dibujar el proceso de intervención que sería más factible utilizar para fortalecer la ética del profesorado universitario cubano que, desde la educación de postgrado, capacitan personal directivo, toda vez que indica que hay que partir de la reflexión para propiciar una adecuada toma de decisiones y, en consecuencia, una correcta actuación.

\section{De la ética general a la ética aplicada; la ética profesional del personal docente universitario}

La ética profesional como disciplina incluida dentro de la ética aplicada es, a decir de varios estudios, la que posibilita regular la actividad que se realiza en el marco de una profesión. Para ser más puntuales, se coincide con Cobo (2001) quien entiende por ética profesional la disciplina que tiene por objeto determinar el conjunto de responsabilidades éticas y morales que surgen en relación con el ejercicio de una profesión, buscando el bien de la clientela o público usuario de los servicios, de la sociedad y de cada profesional.

Específicamente, en el campo profesional educativo, para algunos textos (Jiménez, Luque y Chacin, 2005), la ética contribuye al bienestar y la calidad de vida del estudiantado, disminuyendo las posibilidades de daño o prejuicio sobre este, siendo así; el equipo docente es reconocido y juzgado por la sociedad no solo como persona formadora de conocimientos y habilidades sino también de actitudes consecuentes en el alumnado. Por su parte, Morin (2011) destaca la importancia de formar profesionales de la educación que recuperasen para su profesión el sentido de misión cívica y ética.

En el caso del profesorado universitario que asume un doble encargo, de una parte, forma nuevas generaciones de profesionales y de la otra, capacita y prepara a los grupos ya formados; tiene una responsabilidad ética y social que cumplir y es preciso formarlo para que pueda desempeñarla eficaz y eficientemente.

Al respecto, Manjón (2001) señala que con frecuencia la formación del profesorado universitario se sitúa en la disputa entre enfatizar en la docencia o en la investigación, pero muy pocas veces se considera la preparación actitudinal que debe servir de base para desarrollar competentemente ambos procesos. Desde la perspectiva de esta autora, hay una "actitud central, clave, y esencial que tiene que envolver toda actividad del profesor universitario y es una actitud ética" (Manjón, 2001, p. 3). 
En este orden de ideas, ya García (1971) había hecho referencia a la necesaria formación del profesorado cuando propuso su teoría de la educación personalizada. Para este autor, "la educación personalizada implica un cambio en el concepto de profesor o maestro [y entiende que] el maestro no es simplemente un explicador... el [maestro] tiene por misión provocar en cada alumno el encuentro sujeto-objeto del acto de conocer" (pp. 70-71), lo cual refuerza la idea argumentada.

Para este autor, cuando se hace referencia a la ética del profesorado universitario y su necesaria formación, no se pretende que este se convierta en un predicador moral, sino que lo que se busca es que el profesorado integre en su accionar el saber ser y el saber hacer. Se llama simplemente a compartir que "la tarea de cualquier profesor, si verdaderamente lo es, transciende del puro quehacer intelectual para llegar a todas las manifestaciones de la existencia humana, individual y social" (García, 1984, p. 23).

En este mismo orden de ideas, Cardona (1990), a propósito de la ética en la educación y en la labor del profesional en docencia, coincide en que lo que debe hacer quien educa, como profesional de la enseñanza, es conseguir que su propia tarea sea un acto ético. Toda persona educadora debe actuar éticamente, como persona que interactúa con personas $y$, dar, a esa relación recíproca que se establece, un sentido moralmente bueno. Esta relación debe ser un acto personal bueno en sí y en sus consecuencias. Es importante ser un buen docente siendo un profesor bueno o profesora buena.

Un tanto más reciente, algunos discípulos y discípulas de Víctor García Hoz han unificado esfuerzo para escribir un libro donde, con base en sus planteamientos, los complementan y actualizan con algunas nuevas aportaciones. De esto da fe el artículo publicado en la sesión Reseñas de la Revista Española de Pedagogía por García (2012), la cual conceptualiza:

La educación personalizada atiende a lo que las personas tienen en común, y lo que tienen de propio; aúna las exigencia de la individualización y socialización educativas, y constituye el tipo de educación más acorde con las profundas necesidades humanas y las condiciones del hombre en la sociedad tecnificada en que vivimos; estimula a cada sujeto para que vaya perfeccionando libre y responsablemente la capacidad de dirigir su propia vida; proporciona una formación integral, ...; se ajusta a la existencia de valores universales y objetivos, acordes con el bien, la verdad, la belleza; se ocupa de formar ... el espíritu crítico frente a toda la información que reciben, para que sepan discernir la verdad del error, única forma de evitar la manipulación de las ideas. (párr. 10)

Hay, evidentemente, en todo el legado teórico de García Hoz, importantes y contemporáneos preceptos para desarrollar no solo la educación básica de estos tiempos, sino también una enseñanza de postgrado mucho más pertinente. 
doi: http://dx.doi.org/10.15359/ree.22-3.3

URL: http://www.una.ac.cr/educare

CORREO: educare@una.cr

\section{Metodología}

\section{El diseño de la investigación}

Para profundizar en el estudio de la ética profesional en el contexto universitario, después de analizar los elementos teóricos en la temática de la educación personalizada que, aunque se refiere a la labor profesional en docencia, escasamente se refiere a la labor docente en la enseñanza de postgrado. Teniendo en cuenta que el objeto de estudio ha sido poco explorado en el contexto universitario, se decide desarrollar la investigación desde la perspectiva interpretativa considerando que el interés es comprender las vivencias y percepciones que posee el personal que capacita grupos directivos respecto al tema de la ética (Hernández, Fernán dez y Baptista, 2010). Se organizó un trabajo de campo para proponer una intervención en la formación de personal directivo en Cuba.

\section{Contexto e informantes claves}

Desde hace algunos años se desarrolla en la Universidad de Sancti Spíritus, Cuba, un proyecto de investigación que estudia la concepción cubana acerca de la ética profesional en la enseñanza universitaria, el cual compromete a quienes investigan a adentrarse en el estudio de la ética por considerar este un aspecto imprescindible de cualquier profesional en sentido general y del profesorado universitario en particular.

El trabajo se desarrolla en el contexto de este proyecto y se enfoca a un amplio claustro de docentes de las más altas categorías científicas y académicas de la universidad, quienes se constituyen en informantes clave para esta investigación, actúan como docentes de dos diplomados para personal directivo; uno para el sector de la administración pública y otro para el sector empresarial. Estos diplomados constan de diferentes módulos de asignaturas, como parte de una experiencia nacional iniciada en el año 2012.

Determinar los sujetos informantes clave como muestra en este estudio cualitativo "no es importante desde una perspectiva probabilística, pues el interés del investigador no es generalizar los resultados de su estudio a una población más amplia. [Lo que interesa es]... entender el fenómeno de estudio y responder a las preguntas de investigación" (Hernández et al., 2010).

\section{Proceso de investigación}

El proceso de investigación que permitió llevar a cabo el estudio constó de tres fases fundamentales: fase descriptiva, empírica y valorativa, las cuales permiten cerrar el ciclo desde la perspectiva teórica hasta la validación práctica de la intervención. 


\section{Fase descriptiva}

La fase descriptiva estuvo orientada a describir los elementos esenciales de la ética profesional en el contexto universitario cubano, para lo cual se desarrollaron dos tareas científicas fundamentales:

A) Búsqueda, selección y análisis de la documentación que ofrece información relativa a cuestiones éticas en el contexto universitario cubano.

A partir del objetivo de esta fase se definió como fuente de información fundamental las documentales y como instrumento para la generación de datos la selección y lectura de documentos.

Los documentos que se propusieron revisar fueron:

- Modelo de profesional de las titulaciones de base del profesorado que capacita personas directivas.

- Programas de todas las asignaturas de la disciplina "Docencia Universitaria”, que es una disciplina obligatoria en todas las carreras universitarias, que consta de diferentes asignaturas y que se introdujo para suplir las carencias de formación pedagógica con que egresaban los grupos profesionales de la educación superior.

- Programa del Diplomado “Formación básica para la docencia universitaria”. Diplomado que se imparte a profesores y profesoras noveles de la educación superior en Cuba.

- Regulaciones del trabajo docente metodológico, indicaciones ministeriales, indicaciones del rector.

Para el procesamiento de toda esta información obtenida a partir de las fuentes documentales se decidió emplear el análisis de contenido temático. Para la realización de este se ejecutaron dos tareas principales: una de preanálisis, que fue el primer contacto con la información que aportan los documentos y otra de análisis, que permitió determinar categorías, codificar los datos y separarlos en función de las categorías ya definidas. A partir de estas categorías definidas se volvieron a revisar las transcripciones realizadas, y se elaboraron matrices con la información de cada categoría, lo que posibilitó arribar a conclusiones sobre este aspecto investigado.

B) Estudio de las concepciones que, sobre la ética de su profesión, posee el profesorado universitario cubano que capacita personas directivas en su rol investigativo y de docencia.

Para profundizar en las concepciones que sobre ética profesional posee el profesorado universitario cubano que capacita personas directivas tanto en su rol investigativo como de docentes, se decide aplicar la técnica de grupo de discusión. 
doi: http://dx.doi.org/10.15359/ree.22-3.3

URL: http://www.una.ac.cr/educare

CORREO: educare@una.cr

Los objetivos fundamentales que guiaron la aplicación de esta técnica estuvieron relacionados con:

a. Precisar las regularidades de las opiniones del profesorado hacia la ética profesional docente.

b. Detectar los valores que, a juicio del profesorado, promueve la Universidad en sus estudiantes de postgrado y los que debería promover.

c. Indagar sobre la preparación real del profesorado en temas éticos.

d. Revelar las opiniones del profesorado sobre la necesidad o no de incluir en la preparación del profesorado universitario que capacita personal directivo una materia sobre ética profesional.

La guía de preguntas utilizada para conducir el grupo de discusión fue tomada de García, Ferrández, Sales y Moliner (2006) y adaptada a los propósitos de este estudio.

\section{Guía de preguntas:}

1. ¿Qué competencias caracterizan a un buen o buena profesional en docencia universitaria?

2. ¿Qué entienden por ética profesional docente? ¿A qué contenidos hace referencia?

3. ¿Creen que es necesario un código de ética profesional docente? ¿Qué ámbitos debería regular?

4. ¿Consideran importante la formación ética del profesorado para su buen ejercicio de la docencia y la investigación? ¿Por qué?

5. ¿Es una función de la Universidad enseñar valores solo a sus estudiantes de pregrado? ¿Quévalores consideran debería trasmitir la educación de postgrado en la Universidad?

6. ¿Consideran que los valores de la ética profesional tienen relación con los valores que debe transmitir la Universidad a sus estudiantes de postgrado?

7. ¿Cuáles son las personas profesionales que integran un equipo multidisciplinario de capacitación a personal directivo? ¿Ha recibido todo el grupo de igual manera formación ética desde sus titulaciones de base?

8. ¿Han recibido preparación sobre ética profesional docente? (cómo, quién, a través de qué vías).

9. ¿Consideran importante que exista preparación sobre ética profesional para el profesorado universitario que capacita personas directivas?

10. ¿Qué contenidos consideran necesarios se deberían transmitir en una capacitación de este tipo? 
Para la realización del grupo de discusión se realizó un muestreo no probabilístico intencional a todo el profesorado que participa en la impartición de los diplomados para personas directivas y se establecen como criterios de selección que:

a) pertenecieran a diferentes áreas de conocimiento.

b) existiera variedad de categorías científicas y académicas principales.

c) tuvieran diferentes años de experiencia en la docencia universitaria.

d) hubiera representación de ambos sexos.

El total del profesorado participante fue de 24, pertenecientes a las facultades de Economía, Ingeniería y Humanidades, con categorías docentes de profesorado auxiliar y titular y científicas de maestría y doctorado, con un promedio de 12 años de experiencia en la educación superior y con representatividad de ambos sexos. El grupo trabajó en marzo del 2012 y las intervenciones del profesorado fueron grabadas, así como posteriormente trascritas con auxilio de la ficha preparada para tales efectos.

A continuación, se muestra la Tabla 1 que resume de manera sintética los elementos metodológicos definidos para esta fase descriptiva.

Tabla 1: Fuentes e instrumentos de investigación de la fase descriptiva

\begin{tabular}{|c|c|c|c|}
\hline \multicolumn{4}{|c|}{ Fase descriptiva } \\
\hline Objetivo & Fuente de información & $\begin{array}{l}\text { Instrumentos para la } \\
\text { generación de datos }\end{array}$ & $\begin{array}{c}\text { Instrumento para el } \\
\text { análisis de los resultados }\end{array}$ \\
\hline \multirow[t]{2}{*}{$\begin{array}{l}\text { Describir los elementos } \\
\text { esenciales de la ética } \\
\text { profesional en el contexto } \\
\text { universitario cubano. }\end{array}$} & $\begin{array}{l}\text { Documentales } \\
\text { - Modelos de profesionales, } \\
\text { - programas de asignaturas, } \\
\text { - diplomados, } \\
\text { - indicaciones } \\
\text { metodológicas, del } \\
\text { ministro, del rector }\end{array}$ & $\begin{array}{l}\text { Selección y lectura } \\
\text { de documentos }\end{array}$ & $\begin{array}{l}\text { Análisis de contenido } \\
\text { temático }\end{array}$ \\
\hline & $\begin{array}{l}\text { Orales } \\
\text { - Docentes que capacitan } \\
\text { personal directivo }\end{array}$ & Grupo de discusión & $\begin{array}{l}\text { Análisis de contenido } \\
\text { temático }\end{array}$ \\
\hline
\end{tabular}

Nota: Elaboración propia. 
doi: http://dx.doi.org/10.15359/ree.22-3.3

URL: http://www.una.ac.cr/educare

CORREO: educare@una.cr

\section{Fase empírica}

Cumplimentado el objetivo de la fase descriptiva, que demuestra las debilidades de la formación del personal docente universitario cubano en temas afines a la ética, que limitan sus capacidades para desarrollar una formación personalizada en la enseñanza de postgrado para personal directivo, se pasó a diseñar e implementar una propuesta de intervención que permitiera incidir sobre la ética profesional del profesorado universitario cubano que capacita personal directivo. Dicha propuesta consideró los postulados de Víctor García Hoz, referenciados anteriormente, sobre educación personalizada y el papel del profesorado universitario en este tipo de educación.

\section{Pautas metodológicas generales de la intervención}

La intervención diseñada se propuso para ser desarrollada durante un período de seis meses. Las etapas de la intervención se programaron para realizarse de manera escalonada, es decir, se trabajó inicialmente para asegurar los supuestos teóricos que, como punto de partida necesitaba el profesorado, se iniciaron los talleres de reflexión, con una finalidad práctica que permite poner al grupo de cursistas en situación de decidir libre y responsablemente el mejor modo de actuación en cada caso. Finalmente se realizaron trabajos en grupo para concebir el código de ética del profesorado universitario que capacita personal directivo.

La muestra del profesorado que participó de la experiencia fue similar a la que participó durante la fase descriptiva y solo se les solicitó, de acuerdo con sus respectivos departamentos, posibilidades objetivas de dedicar tiempo a la experiencia y motivación individual para participar en el estudio.

\section{Fase valorativa}

En esta última fase y con el objetivo de valorar la propuesta de intervención desarrollada para incidir sobre la ética profesional del profesorado universitario que capacita personal directivo a fin de hacer las correcciones pertinentes, se determinó la realización de un proceso evaluativo.

\section{Diseño del protocolo de evaluación}

El proceso evaluativo partió de la preparación del protocolo de evaluación e implicó un reencuentro con la bibliografía especializada y un nuevo enfrentamiento con la toma de decisiones que fueron trascendentales para la investigación. Se hizo necesario determinar cuáles serían los aspectos que podrían ser objeto de valoración, cuáles eran los indicadores o criterios concretos a evaluar y cómo quedarían formuladas las preguntas de evaluación. Las principales decisiones tomadas se recogen en la Tabla 2. 
doi: http://dx.doi.org/10.15359/ree.22-3.3

URL: http://www.una.ac.cr/educare

CORREO: educare@una.cr

Tabla 2: Protocolo de evaluación

\begin{tabular}{|c|c|c|c|}
\hline Aspectos a valorar & Objeto & Criterios & Preguntas para la valoración \\
\hline \multirow[t]{10}{*}{$\begin{array}{l}\text { El curso de } \\
\text { superación } \\
\text { profesional } \\
\text { (En su concepción } \\
\text { o diseño) }\end{array}$} & \multirow[t]{2}{*}{$\begin{array}{l}\text { Contenido del } \\
\text { programa del curso }\end{array}$} & $\begin{array}{l}\text { Coherencia entre el } \\
\text { programa del curso y las } \\
\text { bases teóricas en las que } \\
\text { se sustenta }\end{array}$ & $\begin{array}{l}\text { - ¿Hay coherencia entre el programa y las bases teóricas en las que } \\
\text { se sustenta? }\end{array}$ \\
\hline & & Actualización & - ¿Los contenidos del programa están actualizados? \\
\hline & \multirow[t]{3}{*}{$\begin{array}{l}\text { Adecuación al } \\
\text { contexto }\end{array}$} & $\begin{array}{l}\text { Existencia de unos } \\
\text { objetivos previos y de } \\
\text { los procedimientos para } \\
\text { conseguirlos }\end{array}$ & $\begin{array}{l}\text { - ¿Se ha formulado de manera clara lo que se espera conseguir con } \\
\text { el programa del curso? } \\
\text { • ¿Los objetivos previstos y los procedimientos para conseguirlos } \\
\text { están especificados de forma clara y precisa? }\end{array}$ \\
\hline & & Coherencia interna & $\begin{array}{l}\text { - ¿Hay coherencia interna entre los diferentes elementos principales } \\
\text { del programa? }\end{array}$ \\
\hline & & $\begin{array}{l}\text { Carácter orientador } \\
\text { y facilitador de los } \\
\text { componentes del } \\
\text { programa }\end{array}$ & $\begin{array}{l}\text { - ¿Está debidamente fundamentado el curso? } \\
\text { - ¿Los objetivos educativos e instructivos que se proponen son } \\
\text { adecuados para mejorar la excelencia profesional del profesorado } \\
\text { involucrado en el estudio? } \\
\text { - ¿La evaluación propuesta contribuye al logro de los objetivos? } \\
\text { - ¿La bibliografía es adecuada y actualizada para el abordaje de la } \\
\text { temática? }\end{array}$ \\
\hline & \multirow[t]{2}{*}{$\begin{array}{l}\text { Respuesta a } \\
\text { necesidades }\end{array}$} & $\begin{array}{l}\text { Existencia de un } \\
\text { diagnóstico de } \\
\text { necesidades }\end{array}$ & $\begin{array}{l}\text { - ¿El curso se ha diseñado considerando un previo análisis de } \\
\text { necesidades? }\end{array}$ \\
\hline & & $\begin{array}{l}\text { Coherencia entre las } \\
\text { necesidades detectadas } \\
\text { y las priorizadas en el } \\
\text { programa formulado }\end{array}$ & $\begin{array}{l}\text { - ¿Los temas y actividades propuestas en el programa priorizan el } \\
\text { tratamiento a las necesidades detectadas? }\end{array}$ \\
\hline & \multirow[t]{2}{*}{ Viabilidad } & $\begin{array}{l}\text { Congruencia del } \\
\text { programa diseñado con } \\
\text { las características de la } \\
\text { Universidad de Sancti } \\
\text { Spíritus y las de su claustro, } \\
\text { así como del marco social } \\
\text { en el que la institución } \\
\text { está enmarcada }\end{array}$ & $\begin{array}{l}\text { - ¿El programa del curso responde a las políticas definidas? } \\
\text { - ¿El programa del curso respeta las normativas de la educación de } \\
\text { postgrado en Cuba? } \\
\text { - ¿El programa del curso es compatible con el funcionamiento de la } \\
\text { Universidad para la que se propone? } \\
\text { - ¿El programa del curso se ajusta a las características del claustro } \\
\text { para el que fue creado? }\end{array}$ \\
\hline & & $\begin{array}{l}\text { Grado de acuerdo, } \\
\text { apoyo y participación de } \\
\text { la comunidad educativa, } \\
\text { nivel de implicación y } \\
\text { nivel de consenso }\end{array}$ & $\begin{array}{l}\text { - ¿Conocen y apoyan las personas directivas principales de las } \\
\text { facultades y el centro la realización del curso? } \\
\text { • ¿Se han implicado los actores y las actoras claves (claustro del } \\
\text { profesorado de los Diplomados de cuadros) en la implementación } \\
\text { del curso? }\end{array}$ \\
\hline & Factibilidad & Suficiencia & $\begin{array}{l}\text { - ¿El personal responsable del desenvolvimiento del curso es el } \\
\text { adecuado? } \\
\text { - ¿La formación de este personal es adecuada? } \\
\text { - ¿Las metas y recursos son suficientes para llevar a término el curso? }\end{array}$ \\
\hline
\end{tabular}


doi: http://dx.doi.org/10.15359/ree.22-3.3

URL: http://www.una.ac.cr/educare

CORREO: educare@una.cr

\begin{tabular}{|c|c|c|c|}
\hline Aspectos a valorar & Objeto & Criterios & Preguntas para la valoración \\
\hline \multirow[t]{5}{*}{$\begin{array}{l}\text { La intervención } \\
\text { propuesta } \\
\text { (Como un todo) }\end{array}$} & \multirow[t]{5}{*}{$\begin{array}{l}\text { Ejecución de la } \\
\text { intervención }\end{array}$} & Actividades y secuencia & $\begin{array}{l}\text { - ¿Es adecuada la calidad y organización de las actividades que } \\
\text { conformaron la intervención? } \\
\text { - ¿Las actividades desarrolladas durante la intervención se } \\
\text { corresponden con la secuencia en que fueron planificadas? } \\
\text { - ¿La secuencia con que fueron desarrolladas las actividades } \\
\text { posibilitó alcanzar los objetivos propuestos? }\end{array}$ \\
\hline & & Temporalización & $\begin{array}{l}\text { - ¿Consideran que el tiempo y el trabajo invertido en el desarrollo } \\
\text { de la intervención han permitido conseguir los objetivos } \\
\text { propuestos? }\end{array}$ \\
\hline & & Funcionamiento & $\begin{array}{l}\text { - ¿Las decisiones tomadas durante el desarrollo de la intervención } \\
\text { fueron pertinentes? } \\
\text { - ¿Consideran adecuado desde el punto de vista de contenido lo } \\
\text { acontecido en cada una de las tres actividades de la intervención? }\end{array}$ \\
\hline & & Clima & $\begin{array}{l}\text { - ¿Se ha generado un clima de colaboración y participación entre } \\
\text { los actores principales de la intervención? }\end{array}$ \\
\hline & & Utilidad & $\begin{array}{l}\text { - ¿Considera que los conocimientos adquiridos como parte de la } \\
\text { intervención le son de utilidad para su crecimiento personal y } \\
\text { profesional? } \\
\text { •Considera que los conocimientos recibidos y la experiencia } \\
\text { acumulada durante la intervención contribuirán en alguna } \\
\text { medida al logro de su excelencia profesional }\end{array}$ \\
\hline \multirow[t]{2}{*}{$\begin{array}{l}\text { La praxis docente } \\
\text { en la formación de } \\
\text { personal directivo }\end{array}$} & \multirow[t]{2}{*}{$\begin{array}{l}\text { Las actividades } \\
\text { docentes impartidas } \\
\text { en los diplomados } \\
\text { de personal directivo }\end{array}$} & Comportamiento ético & $\begin{array}{l}\text { - ¿Qué virtudes evidencia el personal docente durante su } \\
\text { desempeño en el aula? } \\
\text { •Cómo refuerza el personal docente los valores y actitudes a } \\
\text { través de su clase? } \\
\text { •Cómo se constituye el equipo docente en ejemplo personal a } \\
\text { través de su clase? }\end{array}$ \\
\hline & & Educación personalizada & - ¿Cómo el equipo docente maneja su grupo en el aula? \\
\hline
\end{tabular}

Nota: Elaboración propia.

Preparado el protocolo de evaluación, se procedió a determinar qué instrumento sería el más adecuado para realizar la evaluación del programa propuesto; cómo se aplicaría y quiénes podrían ser informantes clave, que en esta fase y en correspondencia con cada aspecto a valorar, permitirían dar cuenta y evaluar el programa introducido. La Tabla 3 que aparece a continuación refleja estas decisiones tomadas. 
Tabla 3: Relación entre aspectos a valorar, instrumentos de evaluación y el personal evaluador seleccionado

\begin{tabular}{lll}
\hline \multicolumn{1}{c}{ Aspectos a valorar } & \multicolumn{1}{c}{$\begin{array}{c}\text { Instrumento de } \\
\text { evaluación }\end{array}$} & \multicolumn{1}{c}{ Persona evaluadora } \\
\hline $\begin{array}{l}\text { El curso de superación profesional } \\
\text { (En su concepción o diseño) }\end{array}$ & Cuestionario & $\begin{array}{l}\text { Expertos y expertas en educación de } \\
\text { postgrado y en ética profesional docente }\end{array}$ \\
$\begin{array}{l}\text { La intervención propuesta } \\
\text { (Como un todo) }\end{array}$ & Grupo de discusión & $\begin{array}{l}\text { Profesorado que capacita personas } \\
\text { directivas implicadas en el estudio }\end{array}$ \\
$\begin{array}{l}\text { La praxis docente en la formación de } \\
\text { personas directivas (para profesorado } \\
\text { incluidos o no en la intervención) }\end{array}$ & Observaciónparticipante & Investigadora \\
\hline
\end{tabular}

Nota: Elaboración propia.

\section{Resultados y discusión}

Los datos obtenidos por las diferentes técnicas y fuentes empleadas se analizaron previamente utilizando el análisis de contenido temático, a partir de leer las transcripciones párrafo a párrafo para definir el contenido codificándolo, lo cual se muestra en este apartado de forma resumida e integrada luego de triangulada la información.

\section{Resultados fundamentales de la fase descriptiva}

Procesada toda la información proveniente de las diferentes fuentes emergieron las siguientes categorías de análisis: conocimientos previos (CONPRE), conocimientos durante la formación como docente (CONFOR), reguladores del comportamiento (REGCOM), conocimiento tácito (CONTAC) y responsabilidad compartida (RESCOM), que permitieron arribar a los siguientes resultados:

El profesorado que capacita personal directivo proviene de diferentes perfiles, en cada uno de las cuales se tratan algunos aspectos de la ética específica de su futura profesión, más en ningún caso el profesorado había recibido conocimientos previos sobre la ética profesional de la docencia. El profesorado es consciente de esta problemática al exponer:

Durante mi formación como ingeniero ni siquiera recibí conocimientos elementales de pedagogía básica, mucho menos de la ética que debe tener un profesional de la docencia...(MP)

En mis estudios de economía me dieron aspectos de la ética del auditor, mas nunca me imaginé formando directivos, no tengo la menor idea de nada de esto. (CR) 
doi: http://dx.doi.org/10.15359/ree.22-3.3

URL: http://www.una.ac.cr/educare

CORREO: educare@una.cr

Esto coincide con los análisis de contenido realizados a los modelos de profesional de las diferentes titulaciones de base del profesorado que capacita personal directivo, así, por ejemplo, en el de ingeniería industrial dentro del objetivo general se acota "Participar activamente en la vida social demostrando en todas sus acciones una sólida preparación científica-técnica, económica, cultural, política y social sustentada en los valores que deben caracterizar las actitudes de un ingeniero industrial, asumiendo posiciones patrióticas, políticas, ideológicas, éticas y morales ..." (Universidad de Holguín, s. f., Objetivos generales de la carrera, párr. 1). Sin embargo, este objetivo se queda en una formulación que, de por sí solo, no garantiza formar competencias éticas en su profesión, mucho menos en la profesión docente que es lo que interesa a este estudio.

En este sentido, relacionado con la ética profesional del personal docente universitario, Jiménez et al. (2005) han comprobado que cada día ingresan a la educación superior, profesionales en áreas determinadas para desempeñarse como docentes, sin tener la formación específica en el área de educación, dada las exigencias de dichas carreras, y, aun cuando reciben cursos de actualización y capacitación docente, carecen de habilidades para la solución de conflictos profesionales relacionados con la ética.

Respecto a la categoría conocimientos durante la formación como personal docente se encontró que la Disciplina Docencia Universitaria no ha logrado cumplir con sus objetivos, pues en la totalidad de las asignaturas que la conforman no se tratan contenidos de ética profesional de la docencia, elemento que se considera indispensable en la formación de competencias pedagógicas de cualquier docente. De igual forma, el programa del Diplomado "Formación básica para la docencia universitaria" abarca diferentes cursos, más ni como asignaturas, ni como temas específicos dentro de estas se aborda el problema de la ética.

Los elementos reguladores del comportamiento a partir de preceptos éticos están subsumidos en un conjunto de documentos legales docentes como: regulaciones del trabajo metodológico, indicaciones ministeriales y de las rectorías. No existe ningún documento que regule lo relacionado con la ética del profesorado universitario, bien sea en forma de código o de otro tipo.

El profesorado reconoce la ética como un elemento importante dentro de las competencias de un buen o una buena profesional docente de universidad y destaca la necesidad de contar con un código ético para el profesorado, más una buena parte posee conocimientos tácitos al respecto, y emite criterios desde el punto de vista empírico, que no en todos los casos son acertados:

Es obvio que la ética constituye un elemento básico para cualquier profesión, en mi caso siempre he estado claro que la actitud ética de un economista requiere honestidad, transparencia, responsabilidad...y estas deben ser también las de un buen docente..., pero un código siempre ayudaría mucho para ordenar el comportamiento de todos. (AC) 
Para mí la ética si es un aspecto bien importante en todas las profesiones, pero en aquellas en las que trabajamos con personas más, donde el ejemplo es vital y donde los referentes del comportamiento que tenemos como profes es atendido por los que enseñamos... de códigos no sé, nunca había pensado en eso... (MB)

Los sujetos participantes consideran que es responsabilidad de la universidad enseñar valores tanto en la educación de pregrado como de postgrado, solo que, en esta última instancia, el trabajo resulta más complejo. El profesorado opina que toda persona profesional de la docencia debe tener una sólida formación ética a partir de que es formadora de personal formador; pero, de una forma más especial, quienes capacitan personal directivo, pues inciden directamente sobre los grupos líderes o conductores principales de los procesos centrales de la sociedad, por lo que han de ser ejemplo a seguir. Algunas opiniones al respecto lo demuestran:

... el trabajo con la ética y los valores es responsabilidad individual y organizacional y no es privativa de las edades tempranas, también en la formación continua es muy importante. (FR)

La capacitación de directivos exige una sólida formación ética porque el aula tiene que ser laboratorio para dotar a los cursistas de los conocimiento, habilidades y actitudes, desde lo que acontece en el aula. (MC)

...la universidad tiene la responsabilidad de formar valores en todo lo que hace, formación, investigación, extensión y en cualquier modalidad de estudio, el asunto es cómo... (MS)

Puede verse que de la fase descriptiva emergen siete elementos que, de forma general, explican que, aunque los docentes y las docentes que participan en la formación de personal directivo en Cuba reconocen la importancia de portar y conocer la ética de su profesión para poder aportar desde una formación personalizada de postgrado al personal directivo del país, no se cuenta con instrumentos, estrategias o base legal alguna para contribuir a la formación ética del personal docente universitario. Pese a que estos resultados pueden coincidir con lo que ocurre en otros contextos, no fue posible comparar la comparación, pues existen escasos estudios en la bibliografía científica sobre la ética profesional del personal docente universitario en el postgrado.

\section{Resultados fundamentales de la fase empírica}

La intervención resultante quedó pautada en tres etapas fundamentales, cuyos objetivos y tareas se describen en la Figura 1 que aparece seguidamente. 
doi: http://dx.doi.org/10.15359/ree.22-3.3

URL: http://www.una.ac.cr/educare

CORREO: educare@una.cr

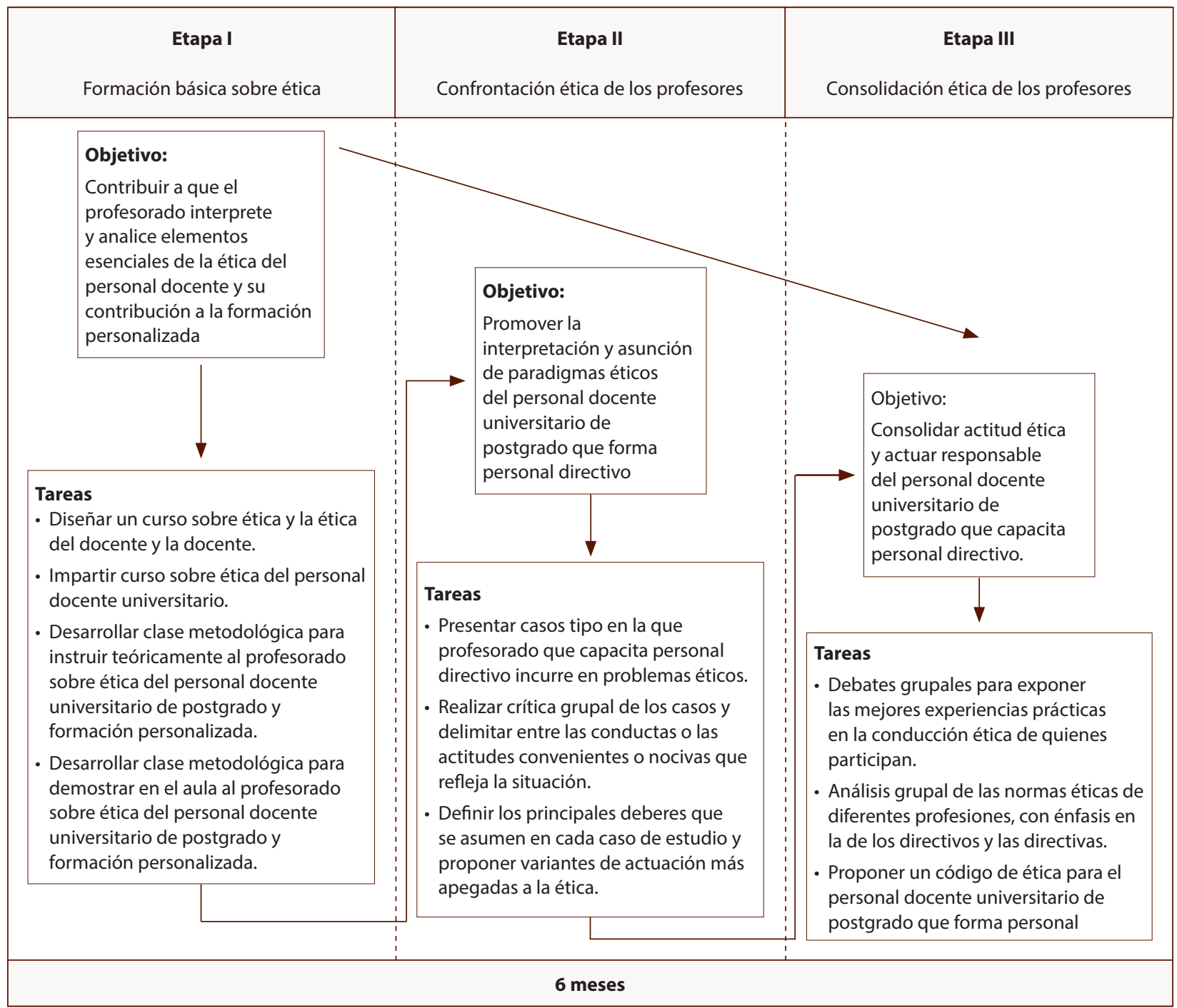

Figura1: Propuesta de intervención sobre la ética del profesorado universitario de postgrado que forma personal directivo.

\section{Resultados fundamentales de la fase valorativa}

Definido el protocolo de evaluación; así como los instrumentos de evaluación y personas evaluadoras de esta fase valorativa y luego de analizados los datos obtenidos de la aplicación de los instrumentos, se pudo arribar a los siguientes resultados para la fase.

En relación con el curso de superación profesional, al triangular por fuente los resultados fundamentales corroboraron que en el curso de superación diseñado a criterio del 
grupo experto consultado, existe coherencia entre el programa y las bases teóricas en las que se sustenta, en la medida en que son definidos conceptos fundamentales; así como los niveles de relación que entre estos se establecen. Coincide, además, en que los contenidos del programa son actualizados, ya que se aborda un aspecto de total vigencia y actualidad en el contexto educativo cubano actual: la ética.

Al hacer referencia a la adecuación al contexto, el grupo experto señala que existen objetivos educativos e instructivos claramente definidos, más los procedimientos para conseguirlos no quedan del todo esclarecidos en los documentos revisados. En sentido general, aprecia la coherencia interna entre los diferentes elementos del programa, aunque a juicio de una parte, el acápite de fundamentación del curso pudo ser más específico para su público destinatario. La bibliografía se considera adecuada a partir de que combina clásicos de la temática con algunos estudios contemporáneos.

Sobre la respuesta a necesidades, el grupo experto corrobora que el diseño del curso ha sido fruto de un análisis minucioso de las necesidades detectadas como parte de la investigación en la fase descriptiva, lo cual valora de positivo.

Asimismo, cataloga el curso de superación de viable a partir de que en él se respetan las políticas y normativas que, en sentido general, tiene el país y que en cuanto a la educación de postgrado específicamente existen, además de que se ajusta a las características del claustro para el que fue creado. Sobre este mismo aspecto, coincidió también en que se aprecia apoyo de las personas directivas de la universidad y facultades implicadas; así como del profesorado comprometido en la investigación.

Finalmente, al valorar la factibilidad del curso, el grupo experto opinó que el personal responsable es el adecuado, que posee buena formación, aunque sobre este aspecto se podría ser aún más ambicioso. La mayor dificultad en este sentido se les atribuye a algunas limitaciones de recursos que inciden sobre un desarrollo óptimo del curso para la consecución de sus objetivos.

Entre tanto, el intercambio con el profesorado que capacita personal directivo que formó parte de la experiencia permitió conocer que, durante la ejecución de la intervención, desde su punto de vista pudieron apreciar una adecuada calidad y organización de las actividades que conformaron la intervención, y se respetó, en todos los casos, la planificación previamente convenida. Consideraron como significativo, además, que la intervención versó sus actividades en lo que había sido deficitario en el diagnóstico de necesidades, es decir, que se combinaron actividades no solo de carácter teórico, sino también actividades que formaran habilidades prácticas en el tratamiento de la ética profesional. Por otra parte, el profesorado también vincula la calidad y organización de la intervención con el nivel de coordinación alcanzado durante la realización de las actividades por parte de los diferentes grupos implicados. 
doi: http://dx.doi.org/10.15359/ree.22-3.3

URL: http://www.una.ac.cr/educare

CORREO: educare@una.cr

Relativo a la dedicación en cuanto a tiempo y al trabajo invertido para conseguir los objetivos de la intervención, el profesorado señala que se trabajó de forma seria y sistemática, más el tiempo dedicado a la intervención lo catalogan de insuficiente para los objetivos propuestos.

Al valorar el criterio de funcionamiento el profesorado considera que las decisiones tomadas durante el desarrollo de la intervención fueron pertinentes y que los contenidos y procedimientos de cada una de las actividades, también lo fueron.

El clima fue el aspecto mejor valorado por los sujetos participantes. De sus criterios es posible extraer la idea de que el clima generado entre los participantes en la intervención fue positivo y primó la colaboración y participación. Según sus propias opiniones, entre estudiantes, la coordinadora de la intervención y las demás personas involucradas en la experiencia se generó un clima distendido, de colaboración e implicación que facilitó el correcto desenvolvimiento de la intervención y el incremento de su motivación intrínseca, a partir de que se estableció una relación que les involucró en la tarea a desarrollar; les hizo partícipes de las decisiones que se tomaban; les impulsó a esforzarse por cumplir con calidad las funciones y exigencias que les fueron asignadas, y les posibilitó enfrentar, de forma constructiva, las dificultades que acontecieron para solucionarlas.

Por último, el profesorado que capacita personas directivas que participaron de la intervención conceden gran utilidad a los conocimientos recibidos para su crecimiento personal y profesional y consideran que esto repercutirá de forma positiva en el logro de su excelencia profesional.

Por su parte, la observación participante permitió corroborar que el profesorado que formó parte de la intervención, a diferencia del que no lo hizo, evidenció durante sus clases, virtudes como: la puntualidad, la ejemplaridad, la responsabilidad, la adecuada presencia personal, el dominio de los contenidos y el respeto al estudiantado, entre otros elementos.

Se observó, además, que dicho equipo docente promovió métodos de enseñanza, estudios de casos y seminarios donde el estudiantado reforzó valores como: la responsabilidad, la solidaridad, la honestidad, humanismo y la laboriosidad; además el amor a la labor como persona directiva, el espíritu de sacrificio y el compromiso con el desarrollo económico y social del país.

La observación demostró que el equipo docente involucrado en la experiencia logró más ejemplaridad en tanto incrementaron la motivación del grupo por su clase, la participación del estudiantado fue más sistemática y mayoritariamente escogieron al profesorado involucrado en la intervención para dirigir científicamente sus trabajos de culminación del diplomado.

Finalmente, la observación demostró que el profesorado involucrado propició un debate democrático en el aula, donde se sintieron libres en su derecho a participar; el estudiantado se condujo en un debate libre para exponer sus criterios y en un clima distendido. 
Triangulado los resultados obtenidos, tanto por fuentes como por métodos, se puede concluir que la intervención propuesta es aceptada por las personas expertas y el profesorado involucrado, según sus propias experiencias y que después de su implementación la observación participante lo corroboró durante la praxis docente.

\section{Conclusiones}

La incorporación de los postulados de García Hoz constituye un acierto para reinterpretar cómo la ética del personal docente se manifiesta en la enseñanza personalizada, trascendiendo su época y contexto para experimentarse en el posgrado de la educación superior cubana, cuando se comparte el significado de que la educación ética combina el ser y el saber hacer y, por tanto, el rol del personal docente universitario va más allá del "puro quehacer intelectual” (García, 1984, p. 23).

Queda claro que el actuar ético del personal que capacita a personas directivas no es la mera combinación de la ética de sus profesiones y la ética profesional de la docencia; ni siquiera la asimilación tácita de dichos conocimientos. La esencia está en la contrastación crítica y reflexiva que el personal docente que capacita personas directivas sea capaz de hacer sobre cómo se transforman sus preceptos éticos, cómo estos impactan en sus prácticas de aula y cómo repercuten en el actuar responsable e integral de las personas que forman.

La universidad tiene la responsabilidad de fomentar la ética entre todo su personal docente, con marcado énfasis de aquel que capacita personal directivo, por su compromiso con la formación de profesionales que dirigen el desarrollo del país. El encargo estatal de formar a todo el personal directivo del país requiere la preparación de un cuerpo docente que cultive y domine valores éticos esenciales, por tanto, el recorrido en la enseñanza de la ética debe ser desde la universidad al profesorado y de estos a la universidad para conformar la actitud ética esencial compartida que generalice una enseñanza cada vez más personalizada.

La experiencia cubana para fortalecer la formación ética del profesorado universitario que capacita personas directivas develó la preparación de profesionales de la universidad para enfrentar los retos de capacitar en estos tiempos, los requerimientos éticos de la educación del posgrado y la dinámica de la responsabilidad compartida entre institución universitaria-profesorado, a partir de la interpretación y análisis de los elementos esenciales de la ética, la asunción de paradigmas éticos y la consolidación de la actitud ética y actuar responsable del personal docente universitario de posgrado que forma directivos y directivas, lo que contribuyó a una educación personalizada.

En futuras investigaciones se propone ampliar el estudio a las percepciones del personal directivo capacitadoy cómo se traduce esto en suactuar ético en el contexto de sus organizaciones. Una arista de la propuesta sería analizar el efecto multiplicador de las prácticas del profesorado universitario en los resultados que obtiene el personal directivo que capacita, y otra consiste en la comparación entre las valoraciones respecto a la ética, que tiene el personal directivo antes de 
doi: http://dx.doi.org/10.15359/ree.22-3.3

URL: http://www.una.ac.cr/educare

CORREO: educare@una.cr

su formación frente a la que muestran una vez que terminada la capacitación. Estos resultados pueden generar procesos que mejoren la educación personalizada al interior de la universidad.

\section{Agradecimientos}

Quienes escriben este texto agradecemos la oportunidad de ser parte del Seminario Internacional de Educación Personalizada (SIEP), desarrollado durante los años 2012 y 2013 y patrocinado por la Universidad Internacional de la Rioja, España, nos dio para profundizar en el estudio de esta temática, contextualizarla en la realidad universitaria cubana y, sobre todo, compartir y aprender.

\section{Referencias}

Bañón-Gómis, A., Guillén-Parra, M. y Ramos-López, N. (2011). La empresa ética y responsable. Universia Business Review, 30, 32-43. Recuperado de http://www.redalyc.org/articulo. oa?id=43318798003

Bautista, O. D. (2005). La ética y la corrupción en la política y la administración pública (Tesis de maestría). Recuperado de http://eprints.ucm.es/7816/1/tesis-maestr\%C3\%ADa 2.pdf p.19

Camps, V. (1996). El malestar en la vida pública. Barcelona: Grijalbo.

Cardona, C. (1990). Ética del quehacer educativo (2a ed.). Madrid: Ediciones Rialp.

Chacón, N. L. (1999). Ética y profesionalidad en la formación de maestros. Revista Formación del profesorado, 35, 41-50. Recuperado de https://dialnet.unirioja.es/servlet/ articulo?codigo $=118030$

Cobo, J. M. (2001). Ética profesional en ciencias humanas y sociales. Madrid: Huerga y Fierro Editores.

Cortina, A. (1997). (Dir.). Rentabilidad de la ética para la empresa (pp. 15-36). Madrid: Fundación Argentaria-Visor.

Cortina, A. (1998). Ética de la empresa. Claves para una nueva cultura empresarial. Madrid: Trotta.

Delors. J. (Preside). (1996). La educación encierra un tesoro. Informe a la UNESCO sobre la educación en el siglo XXI. Madrid: Santillana.

Fereira, E. (2005). Hacía la creación de sistemas de gestión ética. Conferencia celebrada en el Centro de Estudios de Gestión de la Universidad Complutense de Madrid, España.

García, V. (1971). Educación personalizada. Madrid: Instituto de Pedagogía-CSIC.

García, V. (1984). Reflexiones sobre la formación científica y ética de los universitarios. Revista Española de Pedagogía, 42(163), 7-32. 
García, A. (2012). [Reseña del libro Educación personalizada: Principios, técnicas y recursos por B. Carrasco (Ed.)]. Revista Española de Pedagogía, 268. Recuperado de https:// revistadepedagogia.org/informaciones/educacion-personalizada-principios-tecnicas-yrecursos/

García, R., Ferrández, M. R., Sales, M. A. y Moliner, M. O. (2006). Elaboración de instrumentos de medida de las actitudes y opiniones del profesorado universitario hacia la ética profesional docente y su papel como transmisor de valores. RELIEVE, 12(1), 129-149. Recuperado de https://www.uv.es/RELIEVE/v12n1/RELIEVEv12n1 8.pdf

Hernández, R., Fernández, C., \& Baptista, P. (2010). Metodología de la investigación. México D.F: McGraw-Hill.

Hortal, A. (2002). Ética general de las profesiones. Bilbao: Desclée De Brouwer.

Jiménez, N., Luque, M. y Chacín, N. (2005). Ética praxis educativa y práctica pedagógica del docente universitario. Encuentro Educacional, 12(2), 173-193. Recuperado de http:// produccioncientificaluz.org/index.php/encuentro/article/view/871/873

Lemos, E. (Productor) y Carvalho, D. (Director). (1988). Vale tudo [Telenovela]. Brasil: Rede Globo. Recuperado de http://memoriaglobo.globo.com/programas/entretenimento/novelas/ vale-tudo/ficha-tecnica.htm

Manjón, J. (2001). Algunas funciones del profesor universitario para el siglo XXI. Consideraciones éticas. Revista Fuentes, 2, 1-10. Recuperado de https://ojs.publius.us.es/ojs/index.php/ fuentes/article/view/2720/2269

Marina, J. A. (1995). Ética para náufragos. Barcelona: Anagrama.

Morin, E. (2011). La vía para el futuro de la humanidad. Barcelona: Paidós. Recuperado de https:// www.uv.mx/veracruz/cosustentaver/files/2015/09/20.la via para el futuro de la humanidad.pdf

Universidad de Holguín. (s. f.). Carrera de Ingeniería Industrial. Cuba: Autor. http://webcache. googleusercontent.com/search?q=cache:pgCxClbbOXQJ:www.uho.edu.cu/ingenieriaindustrial $-2 /+\& \mathrm{~cd}=2 \& \mathrm{hl}=\mathrm{es} \& \mathrm{ct}=\mathrm{clnk} \& \mathrm{gl}=\mathrm{cr}$

Vargas-Cordero, Z. R. (2014). Elementos esenciales que guían a profesionales que se inician hacia el diseño de un modelo de orientación. Revista Electrónica Educare, 18(1), 265280. Recuperado de http://www.revistas.una.ac.cr/index.php/EDUCARE/article/ view/5572/5405 